\title{
Metode Fuzzy Servqual Dalam Mengukur Kepuasan Pasien Terhadap Kualitas Layanan BPJS Kesehatan
}

\author{
Entin Sutinah ${ }^{1}$, Odilia Rosdiana Simamora ${ }^{2}$ \\ ${ }^{1}$ AMIK BSI Jakarta \\ e-mail: entin.esh@bsi.ac.id \\ ${ }^{2}$ STMIK Nusa Mandiri Jakarta \\ e-mail: odiliasimamora@gmail.com
}

\begin{abstract}
Abstrak
Kurangnya kualitas pelayanan menjadi salah satu kendala terhadap tingkat kepuasan pasien. Pihak rumah sakit juga sering kali kesulitan dalam mengukur kualitas pelayanannya. Tujuan penelitian ini adalah untuk mengetahui tingkat kepuasan pasien yang menggunakan layanan BPJS Kesehatan di Rumah Sakit Umum Daerah Dr. H. Kumpulan Pane. Pengukuran kualitas pelayanan dilakukan dengan metode Fuzzy servqual. Kualitas pelayanan menggunakan lima dimensi yang terdapat dalam servqual yaitu tangibles (bukti fisik), reliability (keandalan), responsiveness (daya tanggap), assurance (jaminan), emphaty (empati). Hasil penelitian ini menunjukkan bahwa nilai gap dari kelima dimensi memiliki nilai negatif. Yang artinya kualitas pelayanan di dapatkan belum sesuai dengan yang diharapkan oleh pasien BPJS Kesehatan. Nilai gap tertinggi adalah dimensi emphaty (empati) dengan nilai gap sebesar 0.15 dan nilai gap terendah adalah dimensi tangibles (bukti fisik) dengan nilai gap 0.49. dengan demikian dapat diketahui bahwa dimensi tangibles (bukti fisik) ini yang menjadi perhatian untuk dapat meningkatkan kualitas pelayanan.
\end{abstract}

Kata Kunci : Fuzzy, Kepuasan, Pelayanan, Servqual

\begin{abstract}
Lack of quality of service becomes one of the obstacles to the level of patient satisfaction. The hospital is also often difficult to measure the quality of service. The purpose of this study is to determine the level of satisfaction of patients who use BPJS Health services in the Regional General Hospital Dr. H. Collection Pane. Measurement of service quality is done by Fuzzy servqual method. Service quality uses the five dimensions contained in the servqual are tangibles (physical evidence), reliability, responseiveness, assurance, empathy. The results of this study indicate that the gap value of the five dimensions has a negative value. Which means the quality of service is not in accordance with the expected by the patient BPJS Health. The highest gap value is the empathy dimension with the gap value of 0.15 and the lowest gap is the dimension of tangibles (physical proof) with the gap value of 0.49. thus it can be seen that the dimensions of tangibles (physical evidence) is of concern to improve service quality.
\end{abstract}

Keywords: Fuzzy, Satisfaction, Service, Servqual

\section{Pendahuluan}

Rumah Sakit Umum Daerah Dr. H. Kumpulan Pane adalah salah satu rumah sakit pemerintah di Kota Tebing Tinggi. Agar mendapat citra yang baik dari masyarakat, Rumah Sakit harus selalu memberikan pelayanan yang maksimal dan tidak membeda-bedakan antar satu pasien dengan pasien yang lainnya dalam memberikan pelayanan untuk setiap pasien yang berobat di rumah sakit umum tersebut. Semakin luasnya Akses layanan Badan Penyelenggara Jaminan Sosial (BPJS) Kesehatan, akan berpengaruh terhadap semakin banyaknya pasien yang akan berobat dengan menggunakan fasilitas BPJS di rumah sakit umum Daerah Dr. H. Kumpulan Pane. Kurangnya kualitas pelayanan menjadi salah satu kendala terhadap tingkat kepuasan pasien. Saat ini pihak rumah sakit seringkali mengalami kesulitan dalam mengukur kualitas 
pelayanannya. Rumah sakit tersebut juga kurang mengetahui berbagai faktor pelayanan yang mempengaruhi Tingkat kepuasan pasien BPJS Kesehatan terhadap pelayanan yang diberikan.

Oleh karenanya perlu dilakukan pengukuran dengan melibatkan pasien yang menggunakan fasilitas layanan BPJS Kesehatan agar upaya peningkatan pelayanan sesuai harapan dengan mengimplementasikan metode fuzzy servqual. Penelitian terkait yang telah menggunakan metode yang sama yaitu:

Kehadiran rumah sakit di Karawang yang makin bertambah yang menyebabkan persaingan yang sangat ketat antar rumah sakit. selain itu juga kesadaran masyarakat akan pentingnya kualitas pelayanan kesehatan yang semakin tinggi, pelayan kesehatan yang profesional dan juga kenyamanan yang dirasakan oleh keluarga dekat pasien guna membantu pemulihan kesehatan pasien yang menjalani rawat inap. untuk mengukur kualitas pelayanan kesehatan pada suatu rumah sakit dengan menggunakan konsep Fuzzy-Servqual yang merupakan teori pengukuran yang mengakomodir bahasa linguistik dan bahasa numeric. hasil dari penggunaaan metode fuzzy servqual dapat dilakukan penilaian kualitas pelayanan pada instalasi rawat inap kelas III sehingga tercipta kualitas pelayanan yang jauh lebih baik dimasa yang akan datang. (Suryapranatha, 2016)

Universitas Dian Nuswantoro ingin melakukan pengukuran kualitas pelayanan akademik. dan layanan tersebut didasarkan pada persepsi indiviu. pelayanan yang akan diukur yaitu bagaimana pihak universitas memberikan layanan untuk mahasiswa seperti akses internet yang memadai, laboratorium komputer yang baik, perpustakaan yang nyaman dan

koleksi bukunya yang lengkap, parkir kendaraan yang nyaman dan aman serta layanan fasilitas yang lain, agar dapat memberikan suatu rekomendasi yang menguntungkan bagi universitas, dalam hal ini memberikan kepuasan bagi mahasiswa serta mencegah ketidakpuasan mahasiswa atas semua layanan fasilitas kampus. penelitian ini menerapkan metode Fuzzy Service Quality terhadap tingkat kepuasan layanan mahasiswa Untuk meningkatkan kualitas layanan Universitas Dian Nuswantoro. (Kartika \& Suprayogi, 2017)
RSUD Panembahan Senopati Bantul adalah Rumah Sakit Umum Daerah di Bantul, rumah sakit tersebut berusaha untuk memberikan suatu layanan kesehatan masyarakat yang yang berkualitas dan hal tersebut merupakan hal yang paling penting untuk dilakukan dalam memberikan pelayanan yang berkualitas kepada pasien, Untuk mengetahui tingkat kualitas, bisa diukur dari harapan dan persepsi pasien dengan menggunakan metode fuzzy servqual dan yang menjadi ukuran kualitas Layanan yang ada meliputi lima dimensi, yaitu reliability, responsiveness, assurance, empati, dan tangibles, sehingga dapat menyelesaikan permasalahan mengenai penilaian kualitas pelayanan terutama di Instalasi Radiologi agar tercipta kualitas pelayanan yang lebih baik di masa yang akan datang. (Suharyanta \& A'yunin, 2012)

Tujuan penelitian ini adalah untuk mengetahui tingkat kepuasan pasien yang menggunakan layanan BPJS Kesehatan di Rumah Sakit Umum Daerah Dr. H. Kumpulan Pane.

fuzzy servqual adalah suatu teori himpunan fuzzy yang dijadikan sarana dalam mempresentasikan ketidakpastian dan merupakan alat untuk memodelkan ketidakpastian yang berkaitan dengan kesamaran, ketidakpastian serta kekurangan mengenai informasi yang berkaitan dengan elemen tertentu dan permasalahan yang dihadapi. (Kusumadewi \& Purnomo, 2010)

BPJS Kesehatan adalah badan hukum yang dibentuk untuk menyelenggarakan program jaminan sosial. (Sembiring, 2016)

Kepuasan adalah suatu keadaan ketika kebutuhan, keinginan, dan harapan pelanggan terpenuhi melalui produk atau jasa yang di konsumsi. (Kaihatu, Achmad, \& Agoes, 2015)

\section{Metode Penelitian}

\section{Metode Pengumpulan Data}

Pada penelitian ini ada beberapa teknik pengumpulan data yaitu:

a. Observasi

Observasi yang dilakukan pada penelitian ini adalah untuk mengetahui secara langsung masalah yang ada di Rumah sakit tersebut yaitu pada bagian pelayanan Pasien BPJS Kesehatan.

b. Wawancara

Peneliti melakukan wawancara langsung dengan pihak rumah sakit maupun 
pasien BPJS untuk memperoleh keterangan guna tujuan penelitian.

c. Kuesioner

Pada penelitian ini dilakukan pembuatan dan penyebaran kuesioner yang ditujukan kepada responden, dan yang menjadi responden adalah pasien yang menggunakan layanan BPJS Kesehatan.

d. Studi Pustaka

Studi Pustaka dilakukan untuk mengumpulkan informasi maupun data yang berhubungan dengan penelitian ini yaitu dengan cara mengambil bahan pustaka dari buku-buku, jurnal, dan internet yang berkaitan dengan penelitian.

\section{Populasi Penelitian}

Yang menjadi populasi dalam penelitian ini adalah seluruh pasien yang menggunakan layanan BPJS Kesehatan, baik yang sudah pernah berobat maupun yang baru pertama kali berobat di Rumah Sakit Umum Daerah Dr. H. Kumpulan Pane. Jumlah populasi pada penelitian ini selama bulan Januari sampai dengan Desember 2016 sebanyak 37.440 pasien. Dengan rata-rata pasien per bulan sebanyak 3.120 pasien.

\section{Sampel Penelitian}

Dalam penelitian ini yang menjadi sampel adalah pasien yang menggunakan layanan BPJS yang datang berobat ke Rumah Sakit Umum Daerah Dr. H. Kumpulan Pane. Untuk menentukan jumlah sampel, peneliti menggunakan pendapat dari Slovin yaitu:

$$
\begin{aligned}
n & =\frac{N}{1+N e^{2}} \\
& =\frac{3120}{1+3120(0,1)^{2}} \\
& =96.894
\end{aligned}
$$

keterangan:

$n=$ Sampel

$\mathrm{N}=$ populasi Sampel

$\mathrm{e}=$ error (kesalahan) 10\%

Agar mendapatkan hasil data yang lebih akurat, maka jumlah responden yang akan dijadikan sampel dan digenapkan menjadi 100 responden.

\section{Hasil dan Pembahasan}

Pada point ini akan membahas hasil penelitian dan membahas langkah-langkah pengolahan data menggunakan metode Fuzzy Servqual yaitu:

\subsection{Pada bagian ini, dijelaskan hasil Identifikasi Variabel-variabel}

Variabel penelitian diperoleh berdasarkan pelayanan yang diberikan oleh pihak RSUD Dr. H. Kumpulan Pane pada pasien yang menggunkan layanan BPJS Kesehatan, dan kemudian dikelompokkan berdasarkan lima dimensi servqual yaitu Tangibles, Reliability, Responsiveness, Assurance, dan Emphaty. Berikut rincian Kriteria penilaian kuesioner tersebut:

1. Kriteria penilaian dan skor dari harapan/ekspektasi adalah sebagai berikut:
a. Sangat tidak penting (STP) = 1
b. Tidak Penting (TP) $=2$
c. Cukup Penting (CP) = 3
d. Penting $(\mathrm{P}) \quad=4$
e. Sangat Penting (SP) $=5$

2. Kriteria penilaian dan skor dari persepsi adalah sebagai berikut:

\begin{tabular}{|c|c|c|}
\hline $\begin{array}{l}\text { No. } \\
\text { Quest }\end{array}$ & Dimensi Servqual & Variabel pernyataan kualitas pelayanan \\
\hline Q1 & \multirow{5}{*}{ Tangibles (Bukti Fisik) } & Setiap ruangan yang di datangi pasien dalam keadaan bersih \\
\hline Q2 & & $\begin{array}{l}\text { Perlengkapan yang digunakan saat pengobatan dalam keadaan } \\
\text { bersih }\end{array}$ \\
\hline Q3 & & Penampilan petugas kesehatan terlihat bersih dan rapih \\
\hline Q4 & & Fasilitas di ruang tunggu sudah modern \\
\hline Q5 & & Rumah sakit memiliki peralatan medis yang lengkap \\
\hline Q6 & \multirow{4}{*}{$\begin{array}{l}\text { Reliability } \\
\text { (Keandalan) }\end{array}$} & Petugas kesehatan memberitahu dengan jelas penyakit pasien \\
\hline Q7 & & Petugas kesehatan sangat handal dalam melayani pasien \\
\hline Q8 & & $\begin{array}{l}\text { Petugas kesehatan menjelaskan dengan benar pada keluarga } \\
\text { cara merawat pasien }\end{array}$ \\
\hline Q9 & & $\begin{array}{l}\text { Petugas kesehatan mendiagnosa penyakit pasien dengan akurat } \\
\text { dan menemukan solusinya }\end{array}$ \\
\hline Q10 & \multirow{3}{*}{$\begin{array}{l}\text { Responsiveness } \\
\text { (Daya Tanggap) }\end{array}$} & Petugas kesehatan sangat tanggap terhadap keluhan pasien \\
\hline Q11 & & Bagian pendaftaran dengan cepat melayani antrian pasien \\
\hline Q12 & & $\begin{array}{l}\text { Petugas kesehatan dengan cepat melayani saat pasien } \\
\text { membutuhkan bantuan }\end{array}$ \\
\hline
\end{tabular}

$\begin{array}{ll}\text { a. Sangat Tidak Puas (STP) } & =1 \\ \text { b. Tidak Puas (TP) } & =2 \\ \text { c. } \quad \text { Cukup Puas (CP) } & =3 \\ \text { d. Puas (P) } & =4 \\ \text { e. Sangat Puas (SP) } & =5\end{array}$

Tabel 1. Variabel Pernyataan 


\begin{tabular}{|c|c|c|}
\hline $\begin{array}{c}\text { No. } \\
\text { Quest }\end{array}$ & Dimensi Servqual & Variabel pernyataan kualitas pelayanan \\
\hline Q13 & & $\begin{array}{l}\text { Petugas kesehatan mau mendengarkan pertanyaan pasien } \\
\text { mengenai penyakit yang diderita pasien }\end{array}$ \\
\hline Q14 & \multirow{3}{*}{ Assurance (Jaminan) } & Petugas kesehatan sudah berpengalaman mengobati pasien \\
\hline Q15 & & Lingkungan rumah sakit terasa nyaman dan tentram \\
\hline Q16 & & $\begin{array}{l}\text { Petugas kesehatan memiliki kemampuan dan pengetahuan } \\
\text { dalam mengobati pasien }\end{array}$ \\
\hline Q17 & \multirow{3}{*}{ Empathy (Empati) } & Petugas kesehatan perhatian pada saat pengobatan berlangsung \\
\hline Q18 & & $\begin{array}{l}\text { Petugas kesehatan berkomunikasi dengan bahasa yang mudah } \\
\text { dimengerti }\end{array}$ \\
\hline Q19 & & Petugas kesehatan minta maaf atas pelayanan yang kurang baik \\
\hline
\end{tabular}

\subsection{Uji Validitas dan Reliabilitas}

Tujuan dari uji validitas ini adalah untuk mengetahui tingkat keakuratan dari sebuah kuesioner. Pada penelitian ini jumlah sampel yang diambil adalah sebanyak 100 responden, dan pengujian validitas dilakukan dengan menggunakan korelasi Pearson Product Moment (koefisien korelasi skor item pertanyaan dengan nilai total). Uji validitas menggunakan taraf signifikan $5 \%$ dan $\mathrm{N}=100$ dengan rumus $\mathrm{df}=\mathrm{n}-2$ maka $\mathrm{df}=100-2$ yaitu 98. Setelah melakukan perhitungan tersebut maka diperoleh $r$ tabel sebesar 0,195. Untuk mengetahui kuesioner sudah valid atau tidak, maka dilakukan perbandingan antara $r$ tabel dengan $r$ hitung. Jika $r$ hitung $>r$ tabel maka kuesioner tersebut dikatakan valid, dan sebaliknya. Berikut ini adalah sample rumus untuk uji validitas persepsi yaitu:

$$
\mathrm{r} \text { hitung }=\frac{n\left(\sum x y\right)-\sum x \sum y}{\left.\sqrt{\left\{n \sum x^{2}-\left(\sum x\right)^{2}\right.}\right\}\left\{n \sum y^{2}-\left(\sum y\right)^{2}\right\}}
$$

keterangan :

$r=$ Korelasi

$x=$ Skor setiap item

$y=$ Skor total dikurangi skor setiap item tersebut

$n=$ Ukuran sampel

1. Uji Validitas Persepsi dan Harapan

$$
\begin{aligned}
& r \text { hitung } \frac{n\left(\sum x y\right)-\sum x \sum y}{\sqrt{\left\{n \sum x^{2}-\left(\sum x\right)^{2}\right\}\left\{n \sum y^{2}-\left(\sum y\right)^{2}\right\}}} \\
= & \frac{100(28568)-(385)(7269)}{\sqrt{\left[100.1567-(385)^{2}\right]\left[100.538317-(7269)^{2}\right]}} \\
= & \frac{2856800-2798565}{\sqrt{[156700-148225][53831700-52838361]}} \\
= & \frac{58235}{\sqrt{8418548025=91752.6459}} \\
= & 0.635
\end{aligned}
$$

Tabel 2. Hasil Uji Validitas Persepsi

\begin{tabular}{|c|l|c|c|}
\hline No & \multicolumn{1}{|c|}{ Variabel pernyataan kualitas pelayanan } & $\begin{array}{c}\text { r Hitung } \\
\text { Persepsi }\end{array}$ & $\begin{array}{c}\mathbf{r} \\
\text { Tabel }\end{array}$ \\
\hline 1 & Setiap ruangan yang di datangi pasien dalam keadaan bersih & 0.635 & 0.195 \\
\hline 2 & $\begin{array}{l}\text { Perlengkapan yang digunakan saat pengobatan dalam keadaan } \\
\text { bersih }\end{array}$ & 0.721 & 0.195 \\
\hline 3 & Penampilan petugas kesehatan terlihat bersih dan rapih & 0.642 & 0.195 \\
\hline 4 & Fasilitas di ruang tunggu sudah modern & 0.753 & 0.195 \\
\hline 5 & Rumah sakit memiliki peralatan medis yang lengkap & 0.651 & 0.195 \\
\hline 6 & Petugas kesehatan memberitahu dengan jelas penyakit pasien & 0.593 & 0.195 \\
\hline 7 & Petugas kesehatan sangat handal dalam melayani pasien & 0.666 & 0.195 \\
\hline 8 & $\begin{array}{l}\text { Petugas kesehatan menjelaskan dengan benar pada keluarga } \\
\text { cara merawat pasien }\end{array}$ & 0.534 & 0.195 \\
\hline 9 & $\begin{array}{l}\text { Petugas kesehatan mendiagnosa penyakit pasien dengan akurat } \\
\text { dan menemukan solusinya }\end{array}$ & 0.676 & 0.195 \\
\hline 10 & Petugas kesehatan sangat tanggap terhadap keluhan pasien & 0.67 & 0.195 \\
\hline 11 & Bagian pendaftaran dengan cepat melayani antrian pasien & 0.583 & 0.195 \\
\hline 12 & $\begin{array}{l}\text { Petugas kesehatan dengan cepat melayani saat pasien } \\
\text { membutuhkan bantuan }\end{array}$ & 0.512 & 0.195 \\
\hline
\end{tabular}




\begin{tabular}{|c|l|c|c|}
\hline No & \multicolumn{1}{|c|}{ Variabel pernyataan kualitas pelayanan } & $\begin{array}{c}\text { r Hitung } \\
\text { Persepsi }\end{array}$ & $\begin{array}{c}\mathbf{r} \\
\text { Tabel }\end{array}$ \\
\hline 13 & $\begin{array}{l}\text { Petugas kesehatan mau mendengarkan pertanyaan pasien } \\
\text { mengenai penyakit yang diderita pasien }\end{array}$ & 0.624 & 0.195 \\
\hline 14 & Petugas kesehatan sudah berpengalaman mengobati pasien & 0.6 & 0.195 \\
\hline 15 & Lingkungan rumah sakit terasa nyaman dan tentram & 0.544 & 0.195 \\
\hline 16 & $\begin{array}{l}\text { Petugas kesehatan memiliki kemampuan dan pengetahuan } \\
\text { dalam mengobati pasien perhatian pada saat pengobatan }\end{array}$ & 0.561 & 0.195 \\
\hline 17 & $\begin{array}{l}\text { Petugas kesehatan perangsung } \\
\text { berlang }\end{array}$ & 0.195 \\
\hline 18 & $\begin{array}{l}\text { Petugas kesehatan berkomunikasi dengan bahasa yang mudah } \\
\text { dimengerti }\end{array}$ & 0.637 & 0.195 \\
\hline 19 & Petugas kesehatan minta maaf atas pelayanan yang kurang baik & 0.564 & 0.195 \\
\hline
\end{tabular}

Tabel 3. Hasil Uji Validitas Harapan

\begin{tabular}{|c|c|c|c|c|}
\hline No & Variabel pernyataan kualitas pelayanan & $\begin{array}{l}r \text { Hitung } \\
\text { Harapan }\end{array}$ & $\begin{array}{c}r \\
\text { Tabel }\end{array}$ & Hasil \\
\hline 1 & Setiap ruangan yang di datangi pasien dalam keadaan bersih & 0.515 & 0.195 & valid \\
\hline 2 & $\begin{array}{l}\text { Perlengkapan yang digunakan saat pengobatan dalam keadaan } \\
\text { bersih }\end{array}$ & 0.601 & 0.195 & valid \\
\hline 3 & Penampilan petugas kesehatan terlihat bersih dan rapih & 0.503 & 0.195 & valid \\
\hline 4 & Fasilitas di ruang tunggu sudah modern & 0.512 & 0.195 & valid \\
\hline 5 & Rumah sakit memiliki peralatan medis yang lengkap & 0.628 & 0.195 & valid \\
\hline 6 & Petugas kesehatan memberitahu dengan jelas penyakit pasien & 0.718 & 0.195 & valid \\
\hline 7 & Petugas kesehatan sangat handal dalam melayani pasien & 0.743 & 0.195 & valid \\
\hline 8 & $\begin{array}{l}\text { Petugas kesehatan menjelaskan dengan benar pada keluarga } \\
\text { cara merawat pasien }\end{array}$ & 0.507 & 0.195 & valid \\
\hline 9 & $\begin{array}{l}\text { Petugas kesehatan mendiagnosa penyakit pasien dengan akurat } \\
\text { dan menemukan solusinya }\end{array}$ & 0.7 & 0.195 & valid \\
\hline 10 & Petugas kesehatan sangat tanggap terhadap keluhan pasien & 0.701 & 0.195 & valid \\
\hline 11 & Bagian pendaftaran dengan cepat melayani antrian pasien & 0.526 & 0.195 & valid \\
\hline 12 & $\begin{array}{l}\text { Petugas kesehatan dengan cepat melayani saat pasien } \\
\text { membutuhkan bantuan }\end{array}$ & 0.568 & 0.195 & valid \\
\hline 13 & $\begin{array}{l}\text { Petugas kesehatan mau mendengarkan pertanyaan pasien } \\
\text { mengenai penyakit yang diderita pasien }\end{array}$ & 0.734 & 0.195 & valid \\
\hline 14 & Petugas kesehatan sudah berpengalaman mengobati pasien & 0.682 & 0.195 & valid \\
\hline 15 & Lingkungan rumah sakit terasa nyaman dan tentram & 0.749 & 0.195 & valid \\
\hline 16 & $\begin{array}{l}\text { Petugas kesehatan memiliki kemampuan dan pengetahuan } \\
\text { dalam mengobati pasien }\end{array}$ & 0.716 & 0.195 & valid \\
\hline 17 & $\begin{array}{l}\text { Petugas kesehatan perhatian pada saat pengobatan } \\
\text { berlangsung }\end{array}$ & 0.56 & 0.195 & valid \\
\hline 18 & $\begin{array}{l}\text { Petugas kesehatan berkomunikasi dengan bahasa yang mudah } \\
\text { dimengerti }\end{array}$ & 0.605 & 0.195 & valid \\
\hline 19 & Petugas kesehatan minta maaf atas pelayanan yang kurang baik & 0.453 & 0.195 & valid \\
\hline
\end{tabular}




\begin{tabular}{|l|l|l|l|l|}
\hline No & Variabel pernyataan kualitas pelayanan & $\begin{array}{c}\text { r Hitung } \\
\text { Harapan }\end{array}$ & $\begin{array}{c}r \\
\text { Tabel }\end{array}$ & Hasil \\
\hline & & & & \\
\hline
\end{tabular}

2. Uji Reliabilitas

Pengujian reliabilitas pada penelitian ini dilakukan dengan menggunakan rumus Cronbach's Alpha yaitu:

Dimana :

$$
r_{11}=\left[\frac{k}{(k-1)}\right]\left[1-\frac{\sum \sigma_{n}^{2}}{\sigma_{t}^{2}}\right]
$$

$r_{11}=$ reliabilitas instrument

$\mathrm{k}$ = banyaknya jumlah butir pertanyaan

$\sigma_{n}^{2}=$ jumlah varian butir atau item

$\sigma_{t}^{2}=$ varian total

berikut adalah perhitungan untuk mencari nilai reliabilitas persepsi.

$r_{11}=\left[\frac{k}{(k-1)}\right]\left[1-\frac{\sum \sigma_{n}^{2}}{\sigma_{t}^{2}}\right]$

$r_{11}=\left[\frac{19}{(19-1)}\right]\left[1-\frac{13.7945}{99.3339}\right]$

$r_{11}=1.0555555556 \times 0.8611299868$

$r_{11}=0.909$

berikut adalah perhitungan untuk mencari nilai reliabilitas harapan.

$$
\begin{aligned}
& r_{11}=\left[\frac{k}{(k-1)}\right]\left[1-\frac{\sum \sigma_{n}^{2}}{\sigma_{t}^{2}}\right] \\
& r_{11}=\left[\frac{19}{(19-1)}\right]\left[1-\frac{9.6746}{70.24}\right] \\
& r_{11}=1.0555555556 \times 0.86225939640 . \\
& r_{11}=0.910
\end{aligned}
$$

Tabel 4. Pedoman Untuk Memberikan Interpretasi Koefisien Korelasi

\begin{tabular}{|c|c|}
\hline Interval Koefisien & Tingkat Hubungan \\
\hline $0.00-0.199$ & Sangat Rendah \\
\hline $0.20-0.399$ & Rendah \\
\hline $0.40-0.599$ & Sedang \\
\hline $0.60-0.799$ & Kuat \\
\hline $0.80-1.000$ & Sangat Kuat \\
\hline \multicolumn{2}{|c|}{ Sumber: (Sugiyono, 2010) }
\end{tabular}

berikut adalah kesimpulan dari hasil uji reliabilitas persepsi dan harapan.

Tabel 5.Kesimpulan Uji Reliabilitas

\begin{tabular}{|c|c|c|}
\hline Kuesioner & Nilai Alpha & Keterangan \\
\hline Persepsi & 0,909 & Sangat Kuat \\
\hline Harapan & 0,910 & Sangat Kuat \\
\hline
\end{tabular}

Berdasarkan hasil dari uji reliabiltas persepsi maka didapatkan nilai alpha 0.909 dengan begitu hasil dari uji reliabilitas dikatakan sangat reliabel. Dan untuk uji reliabilitas harapan didapatkan nilai alpha 0.910, maka dapat disumpulkan bahwa hasil dari uji reliabilitas dikatakan sangat reliabel.

\subsection{Pengolahan Data}

1. Hasil Rekapitulasi Skor

a. Hasil Rekapitulasi skor persepsi

Hasil rekapitulasi skor dari data persepsi didapat dari penjumlahan setiap skor jawaban responden. Dengan kriteria dan skor sebagai berikut:
a) Sangat tidak penting
$=1$
b) Tidak Penting
c) Cukup Penting
d) Penting
e) Sangat Penting
$=1$
$=2$

\begin{tabular}{|c|c|c|c|c|c|c|}
\hline Pernyataan & $\begin{array}{c}\text { Sangat Tidak } \\
\text { puas }\end{array}$ & $\begin{array}{l}\text { Tidak } \\
\text { Puas } \\
\end{array}$ & $\begin{array}{l}\text { Cukup } \\
\text { Puas }\end{array}$ & Puas & $\begin{array}{c}\text { Sangat } \\
\text { Puas }\end{array}$ & \multirow[t]{2}{*}{ TOTAL } \\
\hline & 1 & 2 & 3 & 4 & 5 & \\
\hline Q1 & 2 & 5 & 24 & 44 & 25 & 100 \\
\hline Q2 & 2 & 9 & 25 & 44 & 20 & 100 \\
\hline Q3 & 0 & 4 & 37 & 40 & 19 & 100 \\
\hline Q4 & 1 & 5 & 33 & 43 & 18 & 100 \\
\hline Q5 & 0 & 5 & 29 & 49 & 17 & 100 \\
\hline Q6 & 0 & 2 & 31 & 49 & 18 & 100 \\
\hline Q7 & 0 & 6 & 23 & 46 & 25 & 100 \\
\hline Q8 & 1 & 2 & 33 & 34 & 30 & 100 \\
\hline
\end{tabular}
$=3$
$=4$
$=5$

Tabel 6. Hasil Rekapitulasi Skor Persepsi 


\begin{tabular}{|c|c|c|c|c|c|c|}
\hline \multirow{2}{*}{ Pernyataan } & $\begin{array}{c}\text { Sangat Tidak } \\
\text { puas }\end{array}$ & $\begin{array}{c}\text { Tidak } \\
\text { Puas }\end{array}$ & $\begin{array}{c}\text { Cukup } \\
\text { Puas }\end{array}$ & Puas & $\begin{array}{c}\text { Sangat } \\
\text { Puas }\end{array}$ & \multirow{2}{*}{ TOTAL } \\
\cline { 2 - 6 } Q9 & $\mathbf{1}$ & $\mathbf{2}$ & $\mathbf{3}$ & $\mathbf{4}$ & $\mathbf{5}$ & \\
\hline Q10 & 4 & 6 & 28 & 37 & 25 & 100 \\
\hline Q11 & 1 & 4 & 40 & 34 & 21 & 100 \\
\hline Q12 & 1 & 4 & 35 & 39 & 21 & 100 \\
\hline Q13 & 1 & 6 & 27 & 43 & 23 & 100 \\
\hline Q14 & 1 & 3 & 26 & 48 & 22 & 100 \\
\hline Q15 & 0 & 6 & 26 & 53 & 15 & 100 \\
\hline Q16 & 0 & 5 & 23 & 43 & 29 & 100 \\
\hline Q17 & 0 & 2 & 27 & 47 & 24 & 100 \\
\hline Q18 & 0 & 5 & 22 & 44 & 29 & 100 \\
\hline Q19 & 0 & 2 & 31 & 42 & 25 & 100 \\
\hline & & 4 & 32 & 37 & 27 & 100 \\
\hline
\end{tabular}

b. Hasil Rekapitulasi skor harapan

Hasil rekapitulasi skor dari data persepsi didapat dari penjumlahan setiap skor jawaban responden. Dengan kriteria dan skor sebagai berikut:

a) Sangat Tidak Puas $=1$
b) Tidak Puas
$=2$
c) Cukup Puas
$=3$
d) Puas
e) Sangat Puas
$=5$

Tabel 7. Hasil Rekapitulasi Skor Harapan

\begin{tabular}{|c|c|c|c|c|c|c|}
\hline \multirow{2}{*}{ Pernyataan } & $\begin{array}{c}\text { Sangat Tidak } \\
\text { puas }\end{array}$ & $\begin{array}{c}\text { Tidak } \\
\text { Puas }\end{array}$ & $\begin{array}{c}\text { Cukup } \\
\text { Puas }\end{array}$ & $\begin{array}{c}\text { Puas } \\
\text { Puas }\end{array}$ & \multirow{2}{*}{ TOTAL } \\
\cline { 2 - 5 } Q1 & $\mathbf{1}$ & $\mathbf{2}$ & $\mathbf{3}$ & $\mathbf{4}$ & $\mathbf{5}$ & \\
\hline Q2 & 0 & 0 & 20 & 48 & 32 & 100 \\
\hline Q3 & 0 & 1 & 26 & 50 & 23 & 100 \\
\hline Q4 & 0 & 1 & 21 & 57 & 21 & 100 \\
\hline Q5 & 1 & 0 & 28 & 51 & 21 & 100 \\
\hline Q6 & 0 & 1 & 22 & 45 & 31 & 100 \\
\hline Q7 & 0 & 1 & 24 & 48 & 27 & 100 \\
\hline Q8 & 0 & 1 & 21 & 53 & 25 & 100 \\
\hline Q9 & 0 & 0 & 15 & 54 & 31 & 100 \\
\hline Q10 & 0 & 1 & 33 & 44 & 22 & 100 \\
\hline Q11 & 0 & 0 & 22 & 60 & 18 & 100 \\
\hline Q12 & 1 & 0 & 19 & 54 & 27 & 100 \\
\hline Q13 & 0 & 2 & 28 & 48 & 21 & 100 \\
\hline Q14 & 0 & 1 & 22 & 53 & 24 & 100 \\
\hline Q15 & 0 & 0 & 17 & 52 & 31 & 100 \\
\hline Q16 & 0 & 4 & 29 & 46 & 21 & 100 \\
\hline Q17 & 0 & 0 & 23 & 47 & 30 & 100 \\
\hline Q18 & 0 & 0 & 18 & 64 & 18 & 100 \\
\hline Q19 & 0 & 24 & 52 & 24 & 100 \\
\hline
\end{tabular}

2. Penentuan Fuzzy Set

Penentuan Fuzzy Set ini dilakukan untuk menentukan skor dari jawaban responden berdasarkan beberapa kriteria, yaitu Sangat Tidak Baik, Tidak Baik, Cukup Baik, Baik, Sangat Baik. Berikut ini adalah 
cara penentuan fuzzy set dengan grafik dibawah ini:

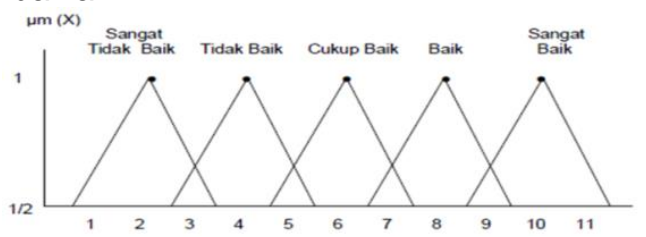

Gambar 1. Penentuan Nilai Fuzzy Set

Sumber: (Suharyanta \& A'yunin, 2012)

\section{Fuzzyfikasi}

Pada tahap ini perhitungan fuzzyfikasi dilakukan untuk mendapatkan nilai batas bawah (c), batas tengah (a), dan batas atas (b) yang merupakan nilai dari Triangular Fuzzy Number (TFN). Untuk menghitung nilai fuzzyfikasi dapat dilakukan dengan rumus sebagai berikut:

Batas bawah(c)

$$
\begin{aligned}
& =\frac{b_{i l} * n_{1}+b_{i l} * n_{2}+b_{i 2} * n_{3}+\ldots \ldots .+b_{i(k-l)} * n_{k}}{n_{1}+n_{2}+n_{3}+\ldots \ldots+n_{k}} \\
& \begin{array}{l}
\text { Batas tengah } \\
\frac{b_{i 1} * n_{1}+b_{i 2} * n_{2}+b_{i 3} * n_{3}+\ldots \ldots .+b_{i k} * n_{k}}{n_{1}+n_{2}+n_{3}+\ldots+n_{k}}
\end{array} \\
& \text { Batas } \\
& \text { atas } \\
& \frac{b_{i 1} * n_{1}+b_{i 3} * n_{2}+\ldots \ldots .+b_{i k} * n_{i(k-1)}+b_{i k} * n_{k}}{n_{1}+n_{2}+n_{3}+\ldots \ldots .+n_{k}}
\end{aligned}
$$

keterangan:

$$
\begin{array}{ll}
\mathrm{b}_{\mathrm{i}} \quad & \text { rata-rata nilai fuzzy set per } \\
& \text { tingkat kepentingan } \\
\mathrm{n} & =\begin{array}{l}
\text { jumlah responden per tingkat } \\
\text { kepentingan }
\end{array}
\end{array}
$$

Berikut adalah bentuk perhitungan fuzzyfikasi untuk tingkat persepsi pada variabel pernyataan Q1 secara manual yaitu:

Batas bawah (c)

$=\frac{(1 \times 2)+(3 \times 5)+(5 \times 24)+(7 \times 44)+(9 \times 25)}{(5)}$

$2+5+24+44+25$

$=\frac{2+15+120+308+225}{100}$

$=\frac{670}{100}=6.7$

Batas tengah (a)

$$
\begin{aligned}
& =\frac{(2.5 \times 2)+(4.4 \times 5)+(6.5 \times 24)+(8.5 \times 44)+(10.5 \times 25)}{2+5+24+44+25} \\
& =\frac{5+22.5+156+374+265.5}{100} \\
& =\frac{820}{100}=8.2
\end{aligned}
$$

Batas atas (b)

$=\frac{(4 \times 2)+(6 \times 5)+(8 \times 24)+(10 \times 44)+(12 \times 25)}{(8+30+192+440+500+44+255}$

$2+5+24+44+25$

$=\frac{8+30+192+440+300}{100}$

$=\frac{970}{100}=9.7$

Perhitungan tersebut dilakukan untuk mencari nilai Triangular Fuzzy number
(TFN) Persepsi pada pernyataan Q1. untuk perhitungan selanjutnya dapat dilakukan dengan cara yang sama. Berikut ini adalah hasil dari fuzzyfikasi persepsi dengan menggunakan software Ms. Excel yaitu:

Tabel 8. Hasil Fuzzyfikasi Persepsi

\begin{tabular}{|c|c|c|c|}
\hline \multirow{2}{*}{$\begin{array}{c}\text { No. } \\
\text { Pernyataan }\end{array}$} & \multicolumn{3}{|c|}{ TFN } \\
\cline { 2 - 4 } & $\mathbf{c}$ & $\mathbf{a}$ & b \\
\hline Q1 & 6.7 & 8.2 & 9.7 \\
\hline Q2 & 6.42 & 7.92 & 9.42 \\
\hline Q3 & 6.48 & 7.98 & 9.48 \\
\hline Q4 & 6.44 & 7.94 & 9.44 \\
\hline Q5 & 6.56 & 8.06 & 9.56 \\
\hline Q6 & 6.66 & 8.16 & 9.66 \\
\hline Q7 & 6.8 & 8.3 & 9.8 \\
\hline Q8 & 6.8 & 8.3 & 9.8 \\
\hline Q9 & 6.46 & 7.96 & 9.46 \\
\hline Q10 & 6.4 & 7.9 & 9.4 \\
\hline Q11 & 6.5 & 8 & 9.5 \\
\hline Q12 & 6.62 & 8.12 & 9.62 \\
\hline Q13 & 6.74 & 8.24 & 9.74 \\
\hline Q14 & 6.54 & 8.04 & 9.54 \\
\hline Q15 & 6.92 & 8.42 & 9.92 \\
\hline Q16 & 6.86 & 8.36 & 9.86 \\
\hline Q17 & 6.94 & 8.44 & 9.94 \\
\hline Q18 & 6.8 & 8.3 & 9.8 \\
\hline Q19 & 6.74 & 8.24 & 9.74 \\
\hline & & & \\
\hline & & & \\
\hline
\end{tabular}

Tabel 9. Hasil Fuzzyfikasi Harapan

\begin{tabular}{|c|c|c|c|}
\hline \multirow{2}{*}{ No. Pernyataan } & \multicolumn{3}{|c|}{ TFN } \\
\cline { 2 - 4 } & c & a & b \\
\hline Q1 & 7.24 & 8.74 & 10.24 \\
\hline Q2 & $6.9 s$ & 8.4 & 9.9 \\
\hline Q3 & 6.96 & 8.46 & 9.96 \\
\hline Q4 & 6.86 & 8.36 & 9.86 \\
\hline Q5 & 7.08 & 8.58 & 10.08 \\
\hline Q6 & 7.02 & 8.52 & 10.02 \\
\hline Q7 & 7.04 & 8.54 & 10.04 \\
\hline Q8 & 7.32 & 8.82 & 10.32 \\
\hline Q9 & 6.74 & 8.24 & 9.74 \\
\hline Q10 & 6.92 & 8.42 & 9.92 \\
\hline
\end{tabular}




\begin{tabular}{|c|c|c|c|}
\hline \multirow{2}{*}{ No. Pernyataan } & \multicolumn{3}{|c|}{ TFN } \\
\cline { 2 - 4 } & c & a & b \\
\hline \multirow{2}{*}{ Q11 } & 7.16 & 8.66 & 10.16 \\
\hline Q12 & 6.72 & 8.22 & 9.72 \\
\hline Q13 & 7 & 8.5 & 10 \\
\hline Q14 & 7.28 & 8.78 & 10.28 \\
\hline Q15 & 6.68 & 8.18 & 9.68 \\
\hline Q16 & 7.14 & 8.64 & 10.14 \\
\hline Q17 & 7 & 8.5 & 10 \\
\hline Q18 & 6.94 & 8.44 & 9.94 \\
\hline Q19 & 7 & 8.5 & 10 \\
\hline
\end{tabular}

harapan. Defuzzyfikasi ini dilakukan untuk mendapatkan nilai tunggal yang representatif. Berikut adalah contoh perhitungan defuzzyfikasi untuk tingkat persepsi pada variabel pernyataan Q1 dengan menggunakan rumus Arithmatic Mean Yaitu

$$
\begin{aligned}
& \mu \boldsymbol{A} \cap \boldsymbol{B}=(\mu \boldsymbol{A}[\boldsymbol{x}]+\mu \boldsymbol{B}[\boldsymbol{y}]) / \mathbf{2} \\
& \mu \boldsymbol{A} \cap \boldsymbol{B}=\frac{8.2+9.7}{2} \\
& =\frac{17.9}{2} \\
& =8.95
\end{aligned}
$$

1. Defuzzyfikasi

\begin{tabular}{|c|c|c|c|c|c|c|}
\hline \multirow{2}{*}{ No. } & \multirow{2}{*}{ Kode Pernyataan } & \multicolumn{3}{|c|}{ TFN } & \multirow{2}{*}{ Defuzzyfikasi } & \multirow{2}{*}{ Rank } \\
\hline & & c & a & b & & \\
\hline 1 & Q1 & 6.70 & 8.20 & 9.70 & 8.95 & 9 \\
\hline 2 & Q2 & 6.42 & 7.92 & 9.42 & 8.67 & 18 \\
\hline 3 & Q3 & 6.48 & 7.98 & 9.48 & 8.73 & 15 \\
\hline 4 & Q4 & 6.44 & 7.94 & 9.44 & 8.69 & 17 \\
\hline 5 & Q5 & 6.56 & 8.06 & 9.56 & 8.81 & 12 \\
\hline 6 & Q6 & 6.66 & 8.16 & 9.66 & 8.91 & 10 \\
\hline 7 & Q7 & 6.80 & 8.30 & 9.80 & 9.05 & 4 \\
\hline 8 & Q8 & 6.80 & 8.30 & 9.80 & 9.05 & 5 \\
\hline 9 & Q9 & 6.46 & 7.96 & 9.46 & 8.71 & 16 \\
\hline 10 & Q10 & 6.40 & 7.90 & 9.40 & 8.65 & 19 \\
\hline 11 & Q11 & 6.50 & 8.00 & 9.50 & 8.75 & 14 \\
\hline 12 & Q12 & 6.62 & 8.12 & 9.62 & 8.87 & 11 \\
\hline 13 & Q13 & 6.74 & 8.24 & 9.74 & 8.99 & 7 \\
\hline 14 & Q14 & 6.54 & 8.04 & 9.54 & 8.79 & 13 \\
\hline 15 & Q15 & 6.92 & 8.42 & 9.92 & 9.17 & 2 \\
\hline 16 & Q16 & 6.86 & 8.36 & 9.86 & 9.11 & 3 \\
\hline 17 & Q17 & 6.94 & 8.44 & 9.94 & 9.19 & 1 \\
\hline 18 & Q18 & 6.80 & 8.30 & 9.80 & 9.05 & 6 \\
\hline 19 & Q19 & 6.74 & 8.24 & 9.74 & 8.99 & 8 \\
\hline
\end{tabular}

Tahap selanjutnya adalah menghitung nilai Defuzzyfikasi dari persepsi dan

Tabel 10.Hasil Defuzzyfikasi Persepsi 
Tabel 11.Hasil Defuzzyfikasi Harapan

\begin{tabular}{|c|c|c|c|c|c|c|}
\hline \multirow{2}{*}{ No. } & \multirow{2}{*}{ Kode Pernyataan } & \multicolumn{3}{|c|}{ TFN } & \multirow{2}{*}{ Defuzzyfikasi } & \multirow{2}{*}{ Rank } \\
\hline & & c & a & b & & \\
\hline 1 & Q1 & 7.24 & 8.74 & 10.24 & 9.49 & 3 \\
\hline 2 & Q2 & 6.90 & 8.40 & 9.90 & 9.15 & 15 \\
\hline 3 & Q3 & 6.96 & 8.46 & 9.96 & 9.21 & 12 \\
\hline 4 & Q4 & 6.86 & 8.36 & 9.86 & 9.11 & 16 \\
\hline 5 & Q5 & 7.08 & 8.58 & 10.08 & 9.33 & 6 \\
\hline 6 & Q6 & 7.02 & 8.52 & 10.02 & 9.27 & 8 \\
\hline 7 & Q7 & 7.04 & 8.54 & 10.04 & 9.29 & 7 \\
\hline 8 & Q8 & 7.32 & 8.82 & 10.32 & 9.57 & 1 \\
\hline 9 & Q9 & 6.74 & 8.24 & 9.74 & 8.99 & 17 \\
\hline 10 & Q10 & 6.92 & 8.42 & 9.92 & 9.17 & 14 \\
\hline 11 & Q11 & 7.16 & 8.66 & 10.16 & 9.41 & 4 \\
\hline 12 & Q12 & 6.72 & 8.22 & 9.72 & 8.97 & 18 \\
\hline 13 & Q13 & 7.00 & 8.50 & 10.00 & 9.25 & 9 \\
\hline 14 & Q14 & 7.28 & 8.78 & 10.28 & 9.53 & 2 \\
\hline 15 & Q15 & 6.68 & 8.18 & 9.68 & 8.93 & 19 \\
\hline 16 & Q16 & 7.14 & 8.64 & 10.14 & 9.39 & 5 \\
\hline 17 & Q17 & 7.00 & 8.50 & 10.00 & 9.25 & 10 \\
\hline 18 & Q18 & 6.94 & 8.44 & 9.94 & 9.19 & 13 \\
\hline 19 & Q19 & 7.00 & 8.50 & 10.00 & 9.25 & 11 \\
\hline
\end{tabular}

2. Hasil Perhitungan Nilai Gap per pelayanan pada Rumah Sakit Umum Variabel Pernyataan

Nilai gap per variabel pernyataan didapat berdasarkan selisih dari nilai persepsi dan nilai harapan. Hal tersebut digunakan untuk mengetahui kualitas

Daerah Dr. H. Kumpulan Pane. Untuk melihat hasil perhitungan nilai gap per variabel pernyataan dapat dilihat pada tabel dibawah ini:

Tabel 12. Hasil Gap Per Variabel Pernyataan

\begin{tabular}{|c|c|c|c|c|c|}
\hline \multirow{3}{*}{ Dimensi } & $\begin{array}{c}\text { Kode } \\
\text { Pernyataan }\end{array}$ & $\begin{array}{c}\text { Defuzzyfikasi } \\
\text { Persepsi }\end{array}$ & $\begin{array}{c}\text { Defuzzyfikasi } \\
\text { Harapan }\end{array}$ & GAP & Rank \\
\hline \multirow{7}{*}{ Tangibles } & Q1 & 8.95 & 9.49 & -0.54 & 17 \\
\cline { 2 - 6 } & Q2 & 8.67 & 9.15 & -0.48 & 12 \\
\cline { 2 - 6 } & Q3 & 8.73 & 9.21 & -0.48 & 13 \\
\cline { 2 - 6 } & Q4 & 8.69 & 9.11 & -0.42 & 11 \\
\hline \multirow{5}{*}{ Reliability } & Q6 & 8.81 & 9.33 & -0.52 & 14 \\
\cline { 2 - 6 } & Q7 & 8.91 & 9.27 & -0.36 & 10 \\
\cline { 2 - 6 } & Q8 & 9.05 & 9.29 & -0.24 & 5 \\
\cline { 2 - 6 } & Q9 & 9.05 & 9.57 & -0.52 & 15 \\
\hline \multirow{3}{*}{ Responsiveness } & Q10 & 8.65 & 8.99 & -0.28 & 8 \\
\cline { 2 - 6 } & Q11 & 8.75 & 9.17 & -0.52 & 16 \\
\hline
\end{tabular}




\begin{tabular}{|c|c|c|c|c|c|}
\hline \multirow{3}{*}{ Dimensi } & $\begin{array}{c}\text { Kode } \\
\text { Pernyataan }\end{array}$ & $\begin{array}{c}\text { Defuzzyfikasi } \\
\text { Persepsi }\end{array}$ & $\begin{array}{c}\text { Defuzzyfikasi } \\
\text { Harapan }\end{array}$ & GAP & Rank \\
\cline { 2 - 6 } & Q12 & 8.87 & 8.97 & -0.10 & 3 \\
\cline { 2 - 6 } & Q13 & 8.99 & 9.25 & -0.26 & 6 \\
\hline \multirow{4}{*}{ Assurance } & Q14 & 8.79 & 9.53 & -0.74 & 19 \\
\cline { 2 - 6 } & Q15 & 9.17 & 8.93 & 0.24 & 1 \\
\cline { 2 - 6 } & Q16 & 9.11 & 9.39 & -0.28 & 9 \\
\hline \multirow{3}{*}{ Emphaty } & Q17 & 9.19 & 9.25 & -0.06 & 2 \\
\cline { 2 - 6 } & Q18 & 9.05 & 9.19 & -0.14 & 4 \\
\cline { 2 - 6 } & Q19 & 8.99 & 9.25 & -0.26 & 7 \\
\hline
\end{tabular}

Pada tabel tersebut dapat dilihat bahwa rata-rata hasil gap dari persepsi dan harapan memiliki nilai negatif, hanya ada satu variabel pernyataan yang memiliki nilai positif yaitu variabel pernyataan ke 15 lingkungan rumah sakit terasa nyaman dan tentram, dengan nilai gap 0.24. Dari hal tersebut dapat disimpulkan bahwa Pasien BPJS belum merasa puas dengan 18 variabel pernyataan tersebut, dan hanya satu variabel yang sudah mencapai tingkat kepuasan pasien BPJS Kesehatan.

3. Hasil Perhitungan Nilai Gap

Berdasarkan Lima Dimensi Servqual

Dari hasil perhitungan gap antar dimensi servqual maka di dapatkan hasil nilai gap dan rank sebagai berikut:

Tabel 13.Hasil Gap Lima Dimensi Servqual

\begin{tabular}{|l|c|c|c|c|}
\hline \multicolumn{1}{|c|}{$\begin{array}{c}\text { Dimensi } \\
\text { Servqual }\end{array}$} & Persepsi & Harapan & GAP & Rank \\
\hline Tangibles & 8.77 & 9.26 & $\begin{array}{c}- \\
0.49\end{array}$ & 5 \\
\hline Reliability & 8.93 & 9.28 & $\begin{array}{c}- \\
0.35\end{array}$ & 3 \\
\hline Responsiveness & 8.82 & 9.2 & $\begin{array}{c}- \\
0.38\end{array}$ & 4 \\
\hline Assurance & 9.02 & 9.28 & $\begin{array}{c}- \\
0.26\end{array}$ & 2 \\
\hline Emphaty & 9.08 & 9.23 & $\begin{array}{c}- \\
0.15\end{array}$ & 1 \\
\hline
\end{tabular}

Setelah dilakukan pengolahan data pada tiap dimensi, dari tabel di atas dapat dilihat bahwa semua dimensi memiliki nilai negatif. Yang menempati peringkat pertama adalah dimensi Emphaty dengan nilai gap 0.15 , kemudian di peringkat kedua dimensi assurance dengan nilai gap -0.26 , peringkat ketiga dimensi reliability dengan nilai gap 0.35 , peringkat keempat ada dimensi responsiveness dengan nilai gap -0.38 , dan di peringkat kelima yaitu dimensi tangible dengan nilai gap -0.49 . Dari data tersebut dapat disimpulkan bahwa keseluruhan dimensi belum memenuhi harapan dari pasien BPJS tersebut. Dengan demikian dimensi yang menjadi prioritas untuk diperbaiki adalah dimensi tangibles.

\section{Kesimpulan}

Berdasarkan hasil penelitian yang dilakukan maka kesimpulannya yaitu, Berdasarkan pengukuran terhadap lima dimensi kualitas pelayanan didapatkan seluruh dimensi memiliki nilai negatif. Dengan demikian apa yang diharapkan oleh pasien yang menggunakan layanan BPJS Kesehatan belum sesuai dengan kenyataan yang diterima dalam pelayanan. Dalam kelima dimensi servqual ini, nilai gap yang tertinggi adalah dimensi emphaty dengan nilai 0.15 dan nilai gap yang terendah adalah dimensi tangible dengan nilai 0.49 .

Dari hasil tersebut maka dimensi tangibles menjadi perhatian bagi pihak RSUD Dr. H. Kumpulan Pane agar lebih meningkatkan kualitas pelayanannya. Dari nilai gap per variabel pernyataan dalam dimensi kualitas pelayanan hanya terdapat satu nilai yang memiliki nilai positif yaitu variabel pernyataan ke 15 , lingkungan rumah sakit terasa nyaman dan tentram. Dari hal tersebut dapat disimpulkan bahwa 18 variabel pernyataan lainnya belum mencapai tingkat kepuasan dari pasien BPJS Kesehatan.

Saran untuk penelitian selanjutnya dapat mengkonfersi antara metode fuzzy servqual dengan metode yang lainnya agar di dapatkan hasil yang lebih baik dan penulis selanjutnya dapat menemukan kekurangan dan kelebihan dari masingmasing metode yang digunakan. 


\section{Referensi}

Kaihatu, T. S., Achmad, D., \& Agoes, t. L. (2015). Manajemen Komplain. Yogyakarta: Andi Offset.

Kartika, N. F., \& Suprayogi. (2017). Implementasi Fuzzy - Service Quality Terhadap Tingkat Kepuasan Layanan Mahasiswa. Jurnal IImiah SISFOTENIKA, 3849.

Kusumadewi, S., \& Purnomo, H. (2010). Aplikasi Logika Fuzzy untuk Pendukung Keputusan Edisi 2. Yogyakarta: Graha IImu.

Sembiring, J. J. (2016). Hak Dan Kewajiban Pekerja. Jakarta: PT Visimedia Pustaka.

Sugiyono. (2010). Metode Penelitian Pendidikan. Bandung: Alfabeta.

Suharyanta, D., \& A'yunin, Q. (2012). Analisis Tingkat Kualitas Pelayanan Jasa Menggunakan Metode Service Quality (Servqual) Fuzzy Di Instalasi Radiologi Rumah Sakit Umum Daerah (RSUD) Panembahan Senopati Bantul. KESMAS, 27-50.

Suryapranatha, D. (2016). Analisis Tingkat Pelayanan Jasa Menggunakan Metode Service Quality (Servqual)Fuzzy Di Instalasi Rawat Inap Kelas III Suatu Rumah Sakit. Jurnal Buana IImu, 56-65. 